\title{
Avaliação psicológica direcionada a populações específicas: técnicas, métodos e estratégias
}

\author{
Marlene Alves da Silva ${ }^{1}$ \\ UNIGRAD - Pós-graduação e Extensão, Vitória da Conquista-BA, Brasil
}

O uso da avaliação psicológica tem se expandido nos últimos tempos. Qualificá-la, dotá-la de cientificidade, ampliar seu raio de atuação implica não só o desenvolvimento de instrumentos adequados e éticos ao fazer psicológico, bem como sua interface com outras ciências. Nesse sentido, pesquisadores da área têm se debruçado no estudo e conhecimento de populações minoritárias e específicas, tais como deficientes, superdotados, atletas com alto rendimento e pessoas com quadros clínicos, dentre outras, visando adequação coerente dos instrumentos psicológicos e avaliações psicológicas não rotuladoras ou estigmatizantes.

Com vistas a abordar conceitos importantes e específicos, assim como ética, processo de construção de instrumentos psicológicos, seus usos e limitações, Carolina Rosa Campos e Tatiana de Cássia Nakano organizam os textos de modo a oferecer conhecimentos dentro da área da avaliação psicólogica focada em algumas populações específicas e estratégias de inclusão social. O livro está organizado em nove capítulos, os quais são escritos por 16 profissionais da Psicologia e da Fonoaudiologia e referem-se a estudos desenvolvidos por meio de diversos enfoques teóricos e metodológicos, caracterizados como estudos independentes, entretanto, relevantes para a compreensão mais aprofundada nas deficiências e nas altas habilidades, como nas adaptações e construções de instrumentos para a área da avaliação psicológica das minorias.

Carolina Rosa Campos e Tatiana de Cássia Nakano, por meio de visita in loco e entrevistas com a equipe multidisciplinar de duas instituições discorrem sobre Avaliação cognitiva de crianças com deficiência visual: conhecimento de recursos muldisciplinares utilizados nas instituições de atendimento, primeiro capítulo. As autoras entrevistaram psicólogos, pedagogos, terapeutas ocupacionas e educadores físicos e constataram a importância de um trabalho conjunto com uma equipe multidisciplar em parceria com a família. Esse olhar multidisciplinar sobre as dificuldades e capacidades dessa população, assim como os materiais a serem utilizados favorecem a adequação na construção ou adaptação de instrumentos sem viés.

No segundo capítulo, Diretrizes norteadoras para a construção e adaptação de instrumentos psicológicos sob a perspectiva do desenho universal, os pesquisadores Cassandra Melo Oliveira e Carlos Henrique Sancineto da Silva Nunes apresentam o processo de adaptação de um instrumento informatizado que avalia a personalidade de pessoas sem e com deficiência, aplicando-se princípios de desenho universal, a saber, população de avaliação ampla e inclusiva; definição precisa do construto; itens acessíveis e não tendenciosos; testes flexíveis a acomodações; instruções e procedimentos simples, claros e intuitivos; leitura agradável e de máxima inteligibilidade e legibilidade. O texto aponta o roteiro de elaboração e as pesquisas e instrumentos desenvolvidos internacionalmente no contexto educacional, bem como as diretrizes norteadoras de construção sob essa modalidade no Brasil.

Populações com deficiência intelectual: funcionamento comportamental e adaptativo de crianças e adolescentes é tema do terceiro capítulo. As pesquisadoras Gisele da Silva Barandi e Maria Cristina Trigueiro Veloz Teixeira tratam da definição de Deficiência Intelectual - DI que, de acordo com o DSM-5, é considerada uma subcategoria diagnóstica dos Transtornos do Neurodesenvolvimento e inclui a identificação de alguns marcadores diagnósticos, como habilidades intelectuais e adapatativas. Ainda, os procedimentos diretos e indiretos da avaliação comportamental em pessoas com DI e a necessidade de uma avaliação neuropsicológica e outros procedimentos. O capítulo é finalizado com um panorama brasileiro dos instrumentos padronizados de avaliação comportamental de pessoas com transtorno do neurodesenvolvimento.

Rauni Jandé Roama Alves, Ricardo Franco de Lima e Sylvia Maria Ciasca assinam o quarto capítulo, Avaliação neuropsicológica da dislexia do desenvolvimento, em 
que apresenta os aspectos históricos e conceituais, ainda, os critérios diagnósticos de acordo com o CID-10 e as evidências neurobiológicas. Define dislexia como um transtorno de aprendizagem de leitura que deve ser resultante de pertubações em aptidões cognitivas fundamentais e de origem constitucional. A avaliação neuropsicológica é um procedimento que visa inferir e compreender o funcionamento cerebral por meio do desempenho comportamental e pode ser utilizada para várias finalidades. Ela requer raciocínio clínico além de outros conhecimentos. Por fim, os autores descrevem pesquisas realizadas sobre os instrumentos utilizados para a avaliação de dislexia.

No quinto capítulo, Psicomotricidade: histórico, definição e dificuldade de aprendizagem, Cíntia Alves Salgado Azoni e Mariana Coelho Carvalho abordam a psicomotricidade vista como ciência que tem como objetivo estudar o homem por meio de seu corpo em movimento e sua relação com seu mundo interno e externo. A sustentação se dá por três conhecimentos básicos, a saber, o movimento, o intelecto e o afeto. As autoras percorrem pelas funções psicomotoras, como a equilibração, a tonicidade, a lateralização, a noção de corpo, a estruturação espaço-temporal e a praxia global fina, e apresentam uma lista de instrumentos para a avaliação psicomotora. O capítulo é encerrado com a questão escolar e os transtornos do desenvolvimento apresentado pela criança em relação à psicomotricidade.

Larissa Botelho Graça e Orlando Francisco Amodeo Bueno decorrem sobre a Avaliação neuropsicológica em epilepsia do lobo temporal mesial, no sexto capítulo. Epilepsia é uma condição neurológica que consiste em interrupções imprevisíveis e recorrentes do funcionamento elétrico normal do cérebro. O impacto da crise de epilepsia na qualidade de vida do paciente está relacionado a problemas para encontrar e manter-se em um emprego, estresse, baixa autoestima, isolamento social, discriminação e estigma. As autoras analisam como prejuízos na qualidade de vida podem afetar os diversos tipos de memórias: de longo prazo, episódica, semântica, implícita, de curto prazo e operacional e, ainda, a atenção, as funções executivas e a capacidade intelectual. O capítulo é fechado descrevendo as limitações da avaliação e as personalidades históricas que conviveram com essa doença.

Avaliação dos transtornos da personalidade no Brasil: o Inventário Dimensional Clínico de Personalidade é o tema do sétimo capítulo elaborado por Lucas de Francisco Carvalho. Ele inicia definindo personalidade que, de acordo com um consenso geral, é uma inferência abstrata, um conceito, um constructo, e não um fenômeno tangível. Portanto, pode ser entendida como a combinação de diferentes sistemas relacionados aos atributos psicológicos. O autor descreve a teoria que sustenta o Inventário Dimensional dos Transtornos da Personalidade - IDTP e seus estudos psicométricos. Ainda, o autor refere que o instrumento apresentou algumas limitações nos primeiros estudos, gerando um novo instrumento. Relata a evolução dos estudos realizados, descreve as etapas dessa revisão e aponta as perspectivas futuras, além de enfatizar que o instrumento continua em estudos avaliativos.

Walquíria de Jesus Ribeiro contribui com o oitavo capítulo para a obra com Discussões atuais da temática das altas habilidades/superdotação: a questão da nomenclatura/conceituação e sua avaliação. A autora reporta as leis educacionais editadas no Brasil sobre esse tema desde 1970. Ao fazer essa narrativa, aponta as diversas nomenclaturas e conceitos, sendo que atualmente usa-se superdotação/altas habilidades. Apesar disso, não há consenso em relação aos termos. A revisão das terminologias utilizadas no Brasil no período de 2002-2011 detecta apenas 43 artigos, sendo que os termos mais usados são "superdotação", "talento" e "altas habilidades". Os modelos teóricos explicativos para cada termo são apresentados e a conclusão é que há controvérsias no que tange ao uso da nomenclatura para designar as altas habilidades/superdotação.

Fechando a obra, Evandro Morais Peixoto e Tatiana de Cássia Nakano apresentam os Problemas e perspectivas na utilização dos testes psicológicos em psicologia do esporte, nono capítulo. Os autores discutem sobre a importância da criação de instrumentos válidos para a avaliação psicológica no contexto esportivo, em especial, a avaliação de atletas de alto rendimento e habilidade. Declaram que essa avaliação alicerça-se nas mesmas premissas que a Psicologia Geral, ou seja, observação, entrevista, experimentos em laboratório, experimentos pedagógicos e testes psicológicos. Relata sobre as exigências do Conselho Federal de Psicologia para o desenvolvimento de instrumentos psicológicos para a aprovação e utilização no Brasil. Perpassa pelos tipos de referências para interpretação dos escores, apresentando os métodos mais utilizados e as consequências da testagem em Psicologia do Esporte.

Trata-se de uma obra que reúne importantes pensamentos de alguns estudiosos em temáticas da área de avaliação psicológica em contextos poucos pesquisados, assim como as várias formas de aferição em que ressaltam a importância da normatização adequada à população atendida e que sejam verificadas as limitações do teste psicológico, assim como os propósitos para os quais foram criados. Ademais, traçam um caminho da construção de um inventário que avalia a personalidade e a interlocução com outras ciências para o entendimento de alguns distúrbios. Em síntese, o livro tem uma linguagem clara e de fácil compreensão, as referências são atuais e os temas diversificados, portanto, de suma importância para os profissionais que atuam com essa tarefa exclusiva da Psicologia. A leitura é recomendada aos graduandos de Psicologia e aos psicólogos, pois aponta e embasa novas áreas de atuação profissional com vistas à inclusão social do avaliando, com significativo respeito às diferenças das populações específicas e questões éticas que pautam a Psicologia. 


\section{Referência}

Campos, C. R., \& Nakano, T. C. (2014). Avaliação psicológica direcionada a populações específicas: técnicas, métodos e estratégias. São Paulo: Vetor Editora.

\section{Sobre a autora}

Marlene Alves da Silva é psicóloga pela Universidade Metodista de São Paulo e doutorada em Psicologia pela Universidade São Francisco. Atualmente é professora convidada na UNIGRAD Pós-graduação e Extensão, Psicóloga/Diretora da Clínica Fênix Ltda e da Orient Consultoria e Diretora Científica de Psicologia da Associação Bahiana de Clínicas de Trânsito. 